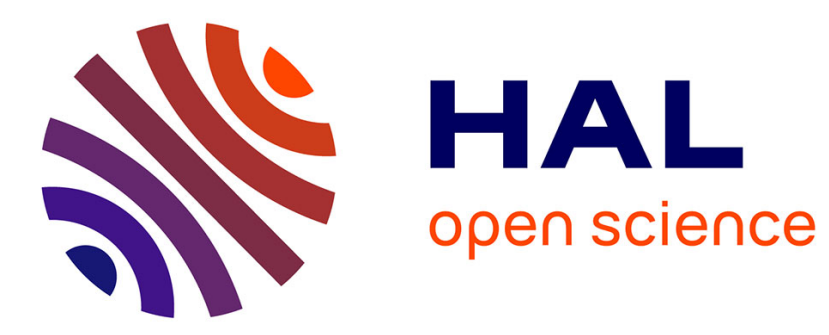

\title{
THE TIME-MARCHED FFP FOR MODELING ACOUSTIC PULSE PROPAGATION
}

\author{
M. Porter
}

\section{To cite this version:}

M. Porter. THE TIME-MARCHED FFP FOR MODELING ACOUSTIC PULSE PROPAGATION. Journal de Physique Colloques, 1990, 51 (C2), pp.C2-659-C2-662. 10.1051/jphyscol:19902153 . jpa00230455

\section{HAL Id: jpa-00230455 https://hal.science/jpa-00230455}

Submitted on 1 Jan 1990

HAL is a multi-disciplinary open access archive for the deposit and dissemination of scientific research documents, whether they are published or not. The documents may come from teaching and research institutions in France or abroad, or from public or private research centers.
L'archive ouverte pluridisciplinaire HAL, est destinée au dépôt et à la diffusion de documents scientifiques de niveau recherche, publiés ou non, émanant des établissements d'enseignement et de recherche français ou étrangers, des laboratoires publics ou privés. 
COLLOQUE DE PHYSIQUE

Colloque C2, supplément au $n^{\circ} 2$, Tome 51, Février 1990

ler Congrès Français d'Acoustique 1990

THE TIME-MARCHED FFP FOR MODELING ACOUSTIC PULSE PROPAGATION

\author{
M.B. PORTER \\ SACLANT Undersea Research Centre, Viale San Bartolomeo 400, I-19026 La \\ Spezia. Italy
}

Résumé - La technique du "Fast-Field Program" est devenue un outil important pour la prédiction de l'affaiblissement de transmission dans un guide d'onde océanique. Ce type de modélisation a été principalement utilisé pour des sources harmoniques: cependant les sources impulsionnelles et en général toute source à large bande peuvent être traîtées similairement en effectuant une synthèse spectrale. Nous développons ici, une technique nouvelle qui fournit une solution directe en propageant la solution dans le temps. Nous illustrerons la méthode en considérant un signal impulsionnel incident sur l'interface entre deux demi-espaces homogènes. Une succession d'images instantanées de l'impulsion illustre graphiquement les ondes réfléchies et transmises.

Abstract - Fast-field programs (FFP's) have emerged as an important tool for predicting transmission loss in an ocean waveguide. Such models have been primarily used for time-harmonic sources; however, pulses or other broadband sources may be treated by Fourier synthesis. We develop a new technique which provides a direct solution by marching the solution forward in time. As an example of the method we consider a pulse incident on an interface between two homogeneous half-spaces. Snapshots of the pulse in time illustrate graphically the effects on the reflected and transmitted waves.

\title{
1 - INTRODUCTION
}

Models for predicting the sound level due to a time-harmonic source in ocean acoustic waveguides have reached a high-level of development. Most problems can then be treated adequately using PE (parabolic equation), NM (normal mode), FFP (fast-field program) or ray/beam techniques depending on the particular approximations which can be made for the problem under consideration.

An area of current research is to extend these time-harmonic models to treat broadband or transient source functions. A time-domain formulation of the PE was developed by McDonald and Kuperman /1/ and applied to both linear and nonlinear problems in ocean acoustics. This approach has been extended by Collins / 2 / to handle wide-angle problems with attenuation. The appeal of this approach is that it bypasses the extra steps of Fourier decomposing the source and synthesizing the field.

In this paper, we develop a new formulation of the fast-field program which is marched directly in the timedomain. The technique is analogous to that used by Alekseyev and Mikhaylenko /3/ for Lamb's problem and extended to more general seismic problems by Olson, Orcutt and Frazier /4/. The basic equations and numerical algorithm are developed in Section 2 and in Section 3 an example of the method is presented for a simple head-wave problem.

\section{2 - GOVERNING EQUATIONS}

The problem we consider is indicated schematically in Fig. 1. We seek the acoustic pressure $p(r, z, t)$ as a function of depth $z$, range $r$, and time $t$ due to an isotropic point source $s(t)$. The material properties characterizing the environment are $\rho(z)$ (density) and $c(z)$ (sound speed). The time-domain FFP is obtained by applying a Fourier-Bessel transform (in range) to the wave equation. That is, we write

$$
\hat{p}(k, z, t)=\int_{0}^{\infty} p(r, z, t) J_{0}(k r) r d r
$$




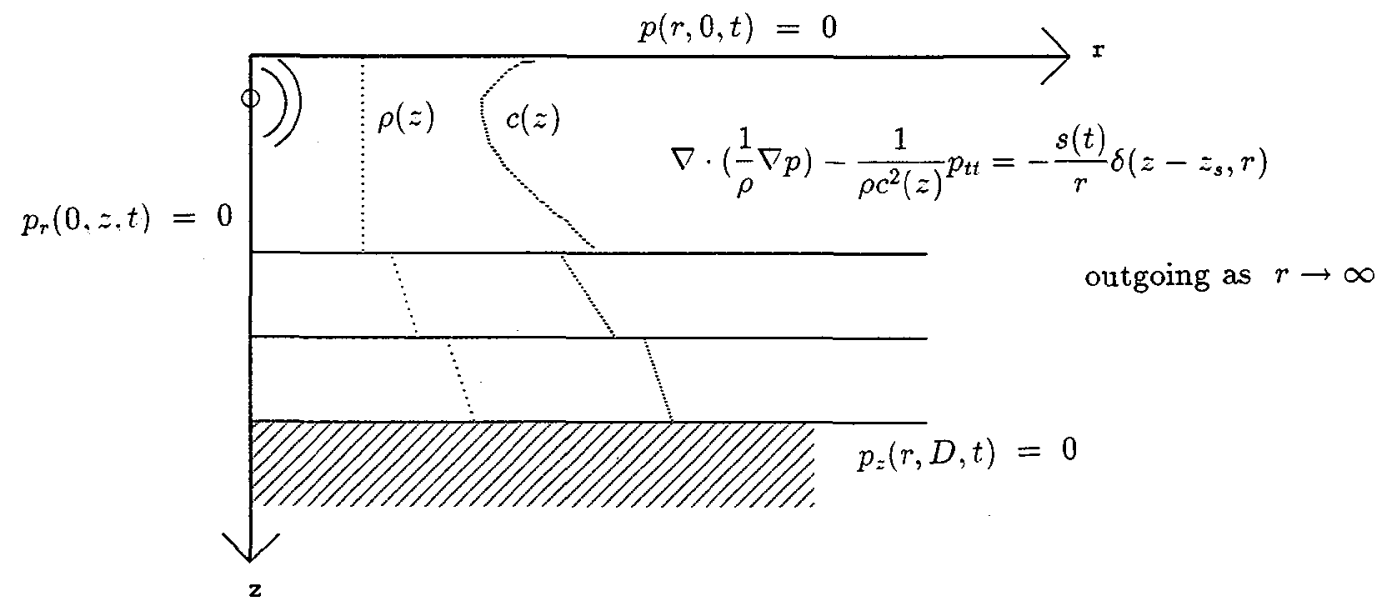

Fig. 1 - Schematic of the model environment.

which leads to,

$$
\frac{\partial}{\partial z}\left(\frac{1}{\rho} \frac{\partial}{\partial z} \hat{p}\right)-\frac{k^{2}}{\rho} \hat{p}-\frac{1}{\rho c^{2}(z)} \hat{p}_{t t}=-s(t) \delta\left(z-z_{s}\right),
$$

together with the boundary and initial conditions:

$$
\begin{aligned}
& \hat{p}(r, 0, t)=\hat{p}_{z}(r, D, t)=0 \\
& \hat{p}(r, z, 0)=\hat{p}_{t}(r, z, 0)=0
\end{aligned}
$$

Equations (2)-(3) are the governing equations for the time-marched FFP. In order to solve these equations numerically, we employ finite elements with "hat" shape functions in depth and finite differences in time. The vector of nodal pressures $p(t)$ is found to satisfy an equation of the form:

$$
\mathbf{K p}-\mathbf{M p}_{t t}=\mathbf{s}(t),
$$

where $\mathbf{M}$ and $\mathbf{K}$ are respectively, the global mass and stiffness matrix obtained by summing the contributions of lumped elemental mass and stiffness matrices given by,

$$
\mathbf{K}_{\mathrm{e}}=\frac{1}{h_{e} \rho^{e}}\left[\begin{array}{rr}
1 & -1 \\
-1 & 1
\end{array}\right]+\frac{h_{e} k^{2}}{6 \rho^{e}}\left[\begin{array}{ll}
3 & 0 \\
0 & 3
\end{array}\right] \quad \mathbf{M}_{e}=\frac{h_{e}}{6 \rho^{e} c_{e}^{2}}\left[\begin{array}{ll}
3 & 0 \\
0 & 3
\end{array}\right] .
$$

For the time discretization, we employ the following finite-difference approximation:

$$
\mathbf{K} \mathbf{p}^{j}-\mathbf{M} \frac{\mathbf{p}^{j+1}-2 \mathbf{p}^{j}+\mathbf{p}^{j-1}}{\Delta t^{2}}=\mathbf{s}^{j},
$$

where $\mathbf{p}^{j}$ denotes the vector of nodal pressures at time step $j$.

The final step is to evaluate the pressure using the inverse Fourier-Bessel transform. As in the standard FFP we shall take advantage of an FFT to evaluate the integral. In order to obtain a suitable form, we replace the Bessel function by its asymptotic approximation and truncate the integral at some finite value. Thus we obtain,

$$
\begin{aligned}
p(r, z, t) & =\int_{0}^{\infty} \hat{p}(k, z, t) J_{0}(k r) k d k \\
& \approx \sqrt{\frac{2}{\pi r}} \int_{0}^{K_{\max }} \hat{p}(k, z, t) \cos (k r-\pi / 4) / \sqrt{k} d k
\end{aligned}
$$

The value of $K_{\max }$ is chosen to sample the highest spatial frequency in the problem and the wavenumber interval is chosen as $\Delta k=2 \pi / R_{\max }$ where $R_{\max }$ is the maximum range to which the pulse will propagate before the calculation is terminated. 


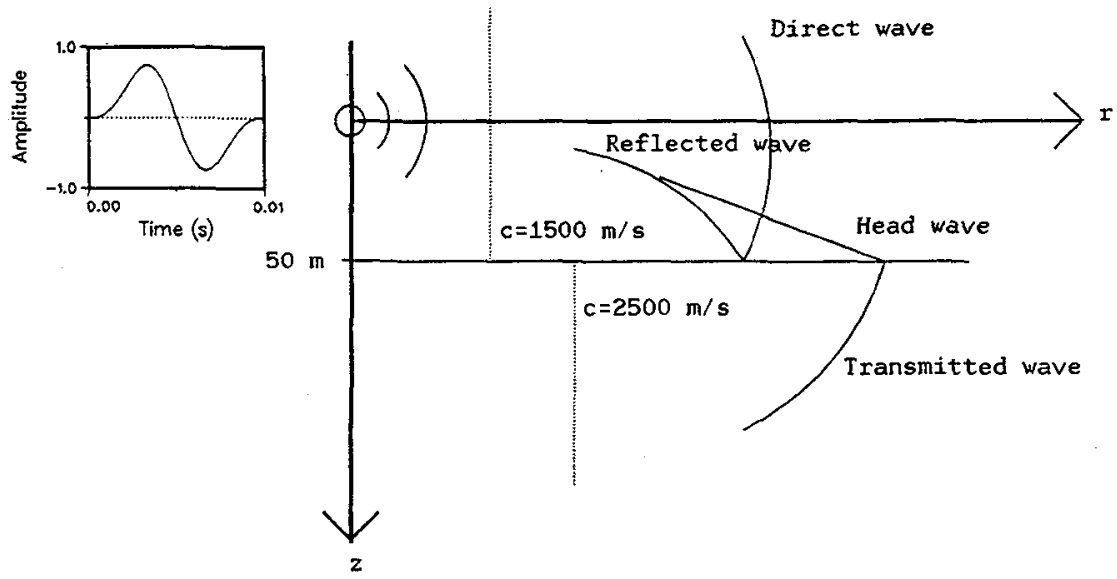

Fig. 2 - Schematic of the head-wave problem.

\section{3 - EXAMPLE: A HEAD WAVE PROBLEM}

As an example, we consider the propagation of an $\mathrm{N}$-shaped pulse in a two half-space problem as indicated in Fig. 2. The particular waveform used is given by,

$$
s(t)= \begin{cases}\sin 2 \pi f_{c} t-0.5 \sin 4 \pi f_{c} t & \text { for } 0<t<1 / f_{c} \\ 0 & \text { else }\end{cases}
$$

where $f_{c}=100 \mathrm{~Hz}$ is a frequency which characterizes the pulse length. The time evolution of the field is plotted in Fig. 3 at times from 20,80 and $120 \mathrm{~ms}$. Note that the pressure has been normalized so that the maximum is unity and also multiplied by a factor of $\sqrt{r}$ to compensate for cylindrical spreading.

In the initial frame we see a spherical wave since the pulse has not yet contacted the interface. In Fig. $3 \mathrm{~b}$ the pulse is beginning to interact with the lower half-space and generating a transmitted and reflected wave. Since the sound speed is higher in the lower half-space, the pulse is longer in the bottom than in the top. The transmission coefficient is less than unity so that the transmitted wave shows a decreased amplitude relative to the direct wave. The reflected wave shows the critical angle effect causing the level to decay so that at steep angles there is virtually no reflected energy.

Finally, in Fig. 3c we can see the wave in the lower half-space has pulled ahead of the direct wave due to the greater wave speed in the bottom. The wavefront of the head wave is also clearly visible forming a line segment starting from the transmitted wave in the lower half-space touching tangentially the reflected wavefront. The head wave is of much lower amplitude than the direct and reflected waves so the scale has been changed to highlight it. The time series for the head wave is roughly a convolution of the source time series $s(t)$ with the Heaviside function, $H(t)$. Thus for our pulse, the head wave is approximately a Gaussian pulse.

\section{4 - SUMMARY}

We have described a Fast Field Program which is marched directly in the time domain and suitable for typical problems in underwater acoustics. The algorithm allows for multiple layers within which the sound speed is an arbitrary smooth function of depth. At the interfaces between layers we allow for possible discontinuities in material properties. Additional terms have also been included to account for attenuation and for advection which is useful for providing a coordinate system which frames the pulse. These extensions are discussed in Ref. [6]. 


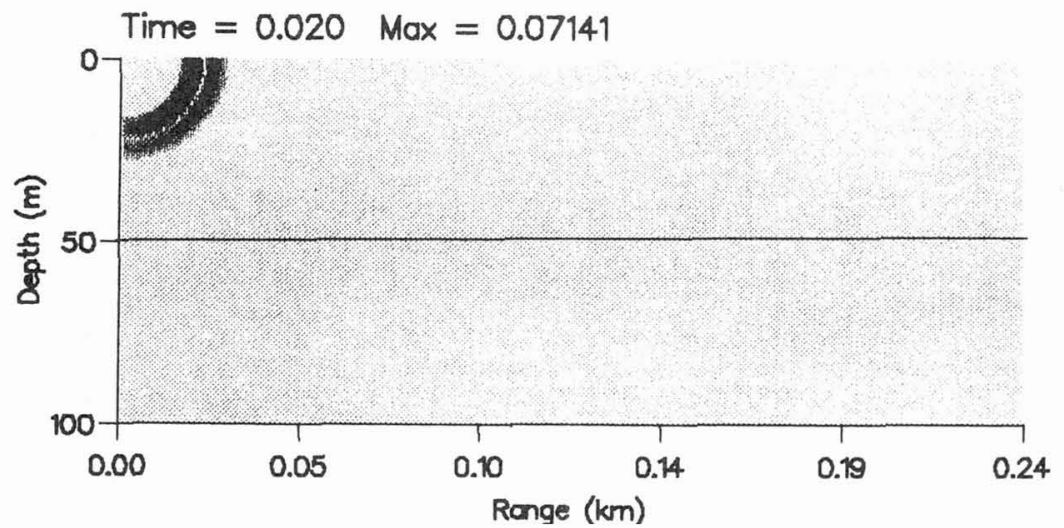

(a)

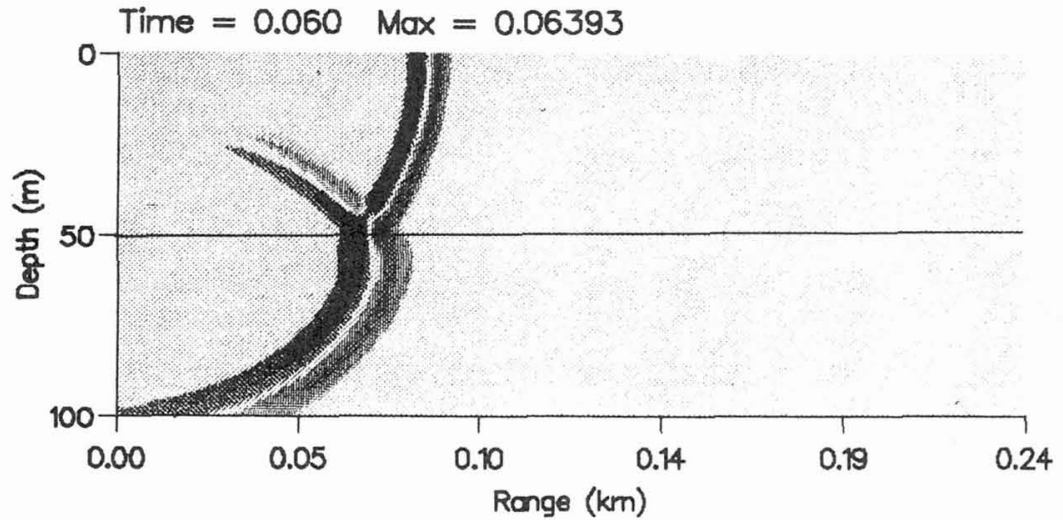

(b)
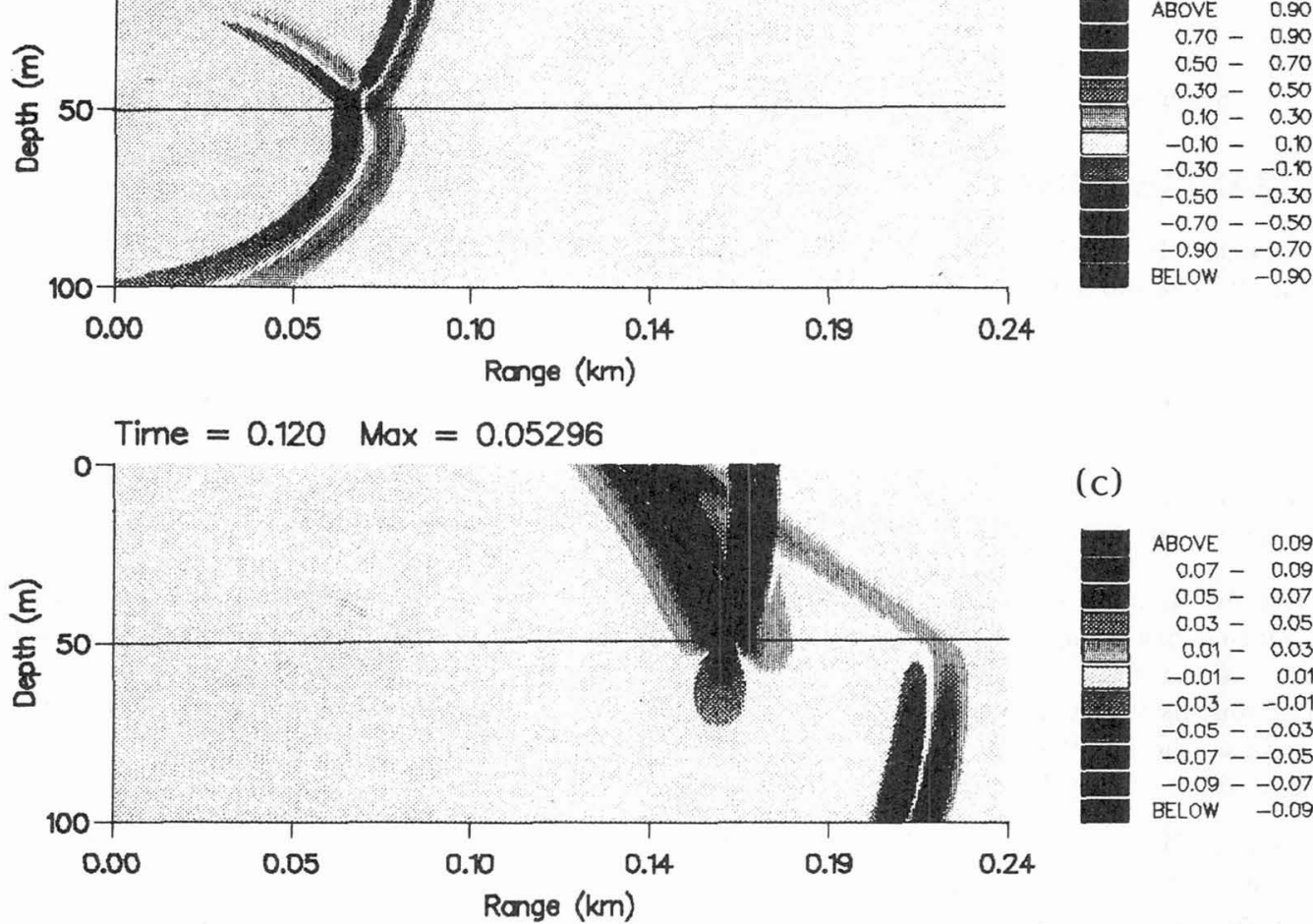

(c)

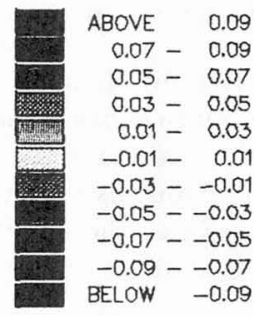

Fig. 3 - Snapshots of the pulse for the head wave problem.

\section{REFERENCES}

/1/ McDonald, B. E. and Kuperman, W. A., J. Acoust. Soc. Am. 81 (1987) 1406.

/2/ Collins, M. D., J. Acoust. Soc. Am. 84 (1988) 2114.

/3/ Alekseyev, A. S. and Mikhaylenko, B. G., Izvestia, Earth Physics $\underline{12}$ (1976) 11.

/4/ Olson, A. H., Orcutt, J. A. and Frazier, G. A., Geophys. J. R. astr. Soc. 77 (1984) 421.

/5/ Schmidt, H. and Jensen, F. B., J. Acoust. Soc. Am. 83 (1985) 571.

/6/ Porter, M., to be published in J. Acoust. Soc. Am. (1990). 